with or traumatised, the better the results. We aim at simplicity and rapidity in our methods, which have been evolved to deal with a large number of patients in a short space of time. No patient with clinically clean eyes has any smear, culture, or other pre-operative investigation, and all are submitted to operation on the day of admission.

In this series we had no case of primary sepsis, and postoperative iritis was, practically speaking, absent. We attribute this freedom from sepsis to a double irrigation of the eye with $1 / 2000$ solution of hydrarg. perchloride at operation coupled with the simplicity of technique and absence of meddlesome surgery.

Our vitreous loss was less than 3 per cent. in the intracapsular method, and this compares with a figure of just under 2 per cent. for our extracapsular cases at this clinic. The advantage gained for the lower vitreous loss of the capsulotomy cases is more than outweighed by the comparatively large incidence of iritis which occurs post-operatively in the extracapsular series.

We hope that this series of cases will convince a fair-minded reader that the adverse criticism which the Smith operation has received is quite undeserved. Moreover, we are convinced that the Smith operation, as outlined above, is the best operation for extraction of uncomplicated senile cataracts in the hands of the surgeon who has to deal with a large number of cases throughout the year.

\title{
AN OPHTHALMOLOGIST IN BUDAPEST AND PRAGUE*
}

BY

L. B. Somerville-Large

DUBLIN

LIKE many ophthalmological colleagues in Great Britain I received an invitation from the Hungarian Medical Trade Union to attend the Centennial Medical Week in Budapest from September 4 th to 12 th-but unlike them all I accepted. As a large number of British ophthalmologists will have happy memories of both ophthalmology in Budapest and of their Hungarian colleagues, a brief note of the meeting may be of interest.

The Centennial Medical Week covered the whole of medicine with ophthalmology as but one of 22 sections. The chairman of

\footnotetext{
* Received for publication, October 18, 1948.
} 
the ophthalmological section was Professor Horay, and the secretary Stephen de Grosz. The main subjects discussed were chemotherapeutics and ophthalmic instruments, although one was invited to choose freely of any subject. Official languages were Hungarian, English, French, German and Russian. Some 50 papers were allotted to the two days of the section's meetings, their duration being limited with an unaccustomed courtesy to " ten minutes for Hungarians and twenty minutes for foreigners." As, with the exception of a few papers in French and German and two in English, all were in Hungarian, I fear that my personal attendance was limited. The papers will be published in due course and need not therefore detain us.

British ophthalmologists may not recollect that the three Budapest professors best known to the English speaking worldEmil de Grosz, Imre and Blaskovics, have died comparatively recently. Their professorial appointments are now filled by Professor Horay and Professor Nonay.

I saw ward cases and attended operations in the First (Prof. Horay) and Second (Prof. Nonay) Eye Clinics and in the eye departments of the Istavan Hospital (Prof. Papolczy) and Janos Hospital (Prof. Csapody). In all four one was stimulated by witnessing exhibitions of faultless surgery, with, unhappily for the spectator, all too few complications. Marked variations in technique of cataract extraction were noticeable. In Prof. Nonay's clinic the retro-bulbar and lid injections were given half an hour before operation, but in Prof. Horay's and Prof. Papolczy's with the patient already on the table. In no case were the lashes cut, and in all the patient walked back to bed. In one clinic masks and caps were dispensed with. All used a superior rectus suturecontrolled by an expert assistant throughout the operation. I only saw intra-capsular extractions-the standard procedure. The capsule was grasped at the " 6 o'clock" periphery and the lens withdrawn without side to side movements-the pressure on the limbus being relied upon to rupture the zonule. A single peripheral iridectomy carried out before extraction was the rule.

A sharp distinction was apparent regarding the advisability of corneal suture. The Imre suture is routine in Prof. Nonay's clinic, and even in his dextrous hands it adds ten minutes to the operation time. A variation of this suture is practised in Prof. Papolczy's clinic. Here, after the insertion of the suture, the section is made but is left just before completion. The conjunctival flap is then cut and finally the section completed with scissors. A difficult procedure, again taking some 10-15 minutes, but giving most beautiful results. Prof. Horay, on the other hand, uses no suture. Dr. de Grosz (son of Emil de Grosz) gave 
a flawless demonstration of Blaskovic's operation for ptosis, and one envied his ability of explaining the steps through French, English and German. We were fortunate enough to see Prof. Csapody carrying out his well-known operation for contracted socket. It appeared a simple and highly satisfactory procedure in his hands.

As only a small number attended the operations, they were perfectly seen, and were a real pleasure to witness.

The doyen of the meeting was Prof. Pascheff of Sofia. This charming, widely-travelled specialist spoke to me of international ophthalmology from Moorfields at the beginning of the century to his own university in Sofia to-day. The visitor who came farthest was Dr. Pascal of New York. He intrigued us by describing a newer and better way to remember the actions of the ocular muscles. To my disappointment Filatov did not come to the meeting, and Russia was unrepresented.

Hungarian hospitality and courtesy is proverbial, to those indeed who have never been in Hungary they come as something of a revelation. To accept all invitations (official and private) was quite impossible, and perhaps my greatest regret was in having to omit Prof. Kettesy's kind invitation to his hospital at the old town of Debrecen in East Hungary. Prof. Weinstein's invitation to his department at the Jewish Hospital in Budapest had unhappily also to be left out of a full programme.

To the uni-lingual English speaker Hungarian ophthalmology is particularly satisfying as it is little exaggeration to say that every specialist speaks English, and the language is so widely read that the British Journal of Ophthalmology, Ophthalmic Literature, American Journal of Ophthalmology, and Excerpta Medica are in almost every clinic. The bond between British and Hungarian Ophthalmology is a very close one, and I can think of few better centres for a clinical tour (and few also where the Englishman would be more welcome) than Budapest, with the provincial clinics at Debrecen (Prof. Kettesy) and Pecs (Prof. Boros) not to be omitted.

In Prague I was fortunate enough to obtain introductions to the No. 1 and No. 2 Eye Clinics, and to Dr. Jermin's clinic at the Bulocka Fiospital. Prof. Kadlicky of the No. 1 Eye Clinic has lately died and his place has not yet been filled. Dr. Dienstbier was kind enough to show me over the fine building and something of their work. Prof. Kurtz is now in charge of No. 2 Eye Clinic which used to be called "The German Clinic" when under Prof. Elschnnig. On the morning of my visit he was doing an operating list of some 55 cases. I timed one hour's operating out of the three I witnessed. In this period Prof. Kurtz did six 
cataract extractions, a squint, a retinal detachment and an iridotomy. Fine theatre technique allowed operative technique to be unhurried. There were two tables in the one theatre, with ocular preparations mostly carried out by the assistants. The theatre was semi-darkened; two really excellent operating lamps of the reflecting type (made by Zeiss of Jena) gave a small brilliant light source over each table. Again I saw faultess intracapsular extractions, and again the lens was delivered with a straight rather than a zig-zag pull. For squint Prof. Kurtz does tenectomy with sometimes an advancement, sewing the muscle in its new position to the limbal lip of a zonal cut made into the sclera-a procedure which might appear somewhat dangerous. Orthoptic Clinics are absent in both Budapest and Prague: In retinal detachment operations the single point diathermy terminal was inserted through the sclera as often as was necessary and the sub-retinal fluid evacuated by scleral incision.

Prof. Kurtz is carrying out Filatov's subconjunctival placental inlay in large numbers of cases and for very many conditions. He also uses placental extract by subconjunctival injection. Retinitis pigmentosa is the only condition that at the present time he feels sure that these procedures assist. The placental tissue in a piece some $10-15 \mathrm{~mm}$. $\times 4 \mathrm{~mm}$. is embedded under the superior bulbar conjunctiva. This can be repeated in some three months. The placenta is untreated apart from being kept for 3-4 days at a temperature of $2^{\circ}-4^{\circ}$ centigrade. In these cases, although central vision is not improved, the field of vision fills out and "night vision " is assisted. In a general hospital that I visited these procedures are also being carried out, the placental tissue being inserted under the skin of the abdominal wall. Large numbers of cases are being done (100 on the morning of my visit) for conditions ranging from Dupuytren's contracture to duodenal ulcer, and from psoriasis to arthritis. Success is undoubtedly achieved, and it would appear that this form of therapy can no longer be neglected.

As in Budapest, so in Prague, hospitality and a courteous welcome were readily granted by one's colleagues everywhere, and everything done to make one's visit interesting and profitable. 